\title{
Importance of Geo-informatics Professional Organizations of the World
}

Rabin K. Sharma

\begin{abstract}
Development of sustainable system in Geoinformatics profession is guided by the professionalism which can be achieved by the professionals through participation in the events of Geo-informatics professional organizations. The professional organizations could be national, regional and international. Each of these organizations has their own objectives to disseminate information and data of research work carried out by the organizations and institutions around the globe. The organizations disseminate the information through different means and media. The professionals should try to acquire those information which will play a role to be benefitted the professionals, institutions and the country itself. So it is believed that professional organizations of the world play an important role for the technological development as well as for the development of professionalism
\end{abstract}

\section{Keywords}

Professional, Geo-informatics Professional organization, Sustainable system, Professionalism, Beneficiaries

\section{Introduction}

Geo-informatics Professional organizations, in general, are non-governmental and non-profitable organizations. It is independent of political ideology and does not discriminate the castes, races, languages and religions. In other words, it accommodates only professionals of the field who has appropriate educational background. The professionals could be academicians, technicians, scientists, manufacturers and students from the corresponding organizations such as governmental, non-governmental, educational, private, consultants, equipment and software manufacturing companies, et cetera related to Geo-informatics profession.

Activities of the professional organizations are the appropriate platforms for the professionals to share, discuss, debate, et cetera for developing consensus to a certain issue or technology which could be best suitable for an organization. There are several Geo-informatics professional organizations in the world which disseminate information amongst the professionals through different means and media such as meeting, workshop, conference, journal, newsletter, web portal, et cetera. Therefore, the system within the professional organization provides opportunity to the professionals around the globe for participation in the event of the organization and the professionals should participate for contributing ideas as much as possible so that other professionals can gain experiences enabling to develop their career and display professionalism which, in turn, able to contribute for the betterment of the organization at work. This justifies, universally, the importance of Geo-informatics professional organization for the technological development.

\section{Category of Geo-informatics Professional Organization}

Geo-informatics professional organizations can be categorized into National, Regional and International organizations. Each has their own role in the professional and technological development. 


\subsection{National Professional Organization}

National Professional Organization is established in a country by a group of related professionals of a particular discipline of the country. Related Geoinformatics professionals could be from the discipline of surveying and mapping, forestry, remote sensing, geology, geodesy, et cetera. Each professional organization defines their own scope of works and objectives. These can be generalized as follows:

- Advocate application of new technology

- Support for formulation of norms, standards and policies for related field

- Create awareness of the technology to the concerned group of people or related organizations

- Disseminate related information and data to the concerned authorities

- Develop an environment to share and discuss about certain issues among the professionals

In Nepal, some of the major professional organizations from geo-informatics domain are Nepal Surveyor's Association (NESA), Nepal Geographical Information System Society (NEGISS), Nepal Remote Sensing and Photogrammetric Society (NRSPS), Geomatics Engineering Society (GES), et cetera [2].

In order to fulfill the objectives of the organization, each organization executes some activities which are in general common to most of the organizations. Some of the common practices are as follows:

- Launch web portal of the organization to post relevant information and news of the profession

- Publish Newsletter and/or Journal with information on recent development of the technologies and appropriate articles from the professionals

- Conduct workshop, seminar, conference, talk program, panel discussion, et cetera to create awareness to the concerned authorities and/or individual professionals

\subsection{Regional Professional Organizations}

Necessity of regional professional organizations are realized because it is not practical and possible to sit together the professionals from all over the world for discussion of some technology or issues related to a particular system. In general, the professionals of under developed and developing countries may not participate in the events when organized in different regions than they are leaving because the cost for the participation may not able to manage unless they found some sponsor. Whereas for the professionals from the developed countries could manage for participation in anywhere in the world and they manage the cost either through the organization they are working or they bear the cost themselves. So a group of professionals from different countries belonging to a certain region establish the professional organization with definite objectives. They organize the activities in one of the countries of their own region so that they expect more participants from the region. At present, African region, Asia and the Pacific region, European region, North American region and South American region are recognized in the world.

In each region, there are so many Geo-informatics professional organizations. Some of the Asia and the Pacific regional organizations are Asian Association on Remote Sensing (AARS), Asia Pacific Regional Space Agency Forum (APRSAF), Permanent Committee on GIS Infrastructure for Asia and the Pacific (PCGIAP), SAARC Networking Arrangement on Cartography (SNAC), et cetera [3].

If the scope of area of the organization is wide, then the organization establishes the working groups and/or establishes a sister regional professional organization to deal with limited scope. For example: Asia Pacific Regional Space Agency Forum (APRSAF) has Earth Observations (EO), Communication Satellite Application (CSA), Space Environment Utilization (SEU) and Space and Education Awareness (SEA) Working Groups and some initiatives namely Sentinal Asia (SA), Space Application for Environment (SAE), The Regional Readiness Review for Key Climate Missions (Climate $\mathrm{R}^{3}$ ) and $\mathrm{KIBO}-\mathrm{ABC}$ which deals with their corresponding issues allocated either by APRSAF or their corresponding Working Group [5]. Each working group and initiative then defines its own progarmmes, conducts the programmes and finally reports the achievements in the plenary session of the 
immediate programme of respective Working Group or APRSAF.

In the case of AARS, working groups are not established and conducts conference once in a year in one of its member countries. However, when the time demands, the Association discussed about some of the current issues such as application of Rice Satellite, disaster occurred by Tsunami, et cetera as a separate activity of AARS.

\subsection{International Professional Organization}

In the course of technological development, several issues and problems could arises which is necessary to resolve for moving ahead. Therefore, scientists from the different parts of the world decided to establish organization representing the interested countries for discussion of the technical issues, identify the research areas, develop technologies for implementing the activities efficiently, educate other professionals and decision makers, et cetera. Based on these concepts, several international professional organizations from Geo-informatics area have been established and some of the International organizations are International Federation of Surveyors (FIG), International Society for Photogrammetry and Remote Sensing (ISPRS), International Steering Committee for Global Mapping (ISCGM), International Cartographic Association (ICA), International Union of Geodesy and Geophysics (IUGG), Group on Earth Observations (GEO), et cetera.

At the same time, new concepts and technologies could evolve, that could lead sometimes to establish a new professional organization. For example, in 1978, Global Positioning System (GPS) was developed for Positioning, Navigations and Timing (PNT) by the United States of America. This is the only system available to the user's communities for many years. At present, number of such systems are emerged for instance, GLONASS from Russia, GALILEO from Europe, and COMPASS/ BEIDOU from China. These systems are identified as global constellations. Furthermore, Regional Constellations as well as Satellite Based Augmented System from different countries around the world are also developed. In order to make use of these systems, not only for Positioning, Navigations and Timing (PNT) but also for non-PNT applications such as to compute wind velocity, height of sea waves, et cetera, a concept of Global Navigation Satellite System (GNSS) was developed. Noticing the growing of such system, Japan Aerospace Exploration Agency (JAXA) established an international organization: "MultiGNSS Asia (MGA)" and initiated "Asia MultiGNSS Demonstrative Campaign" for promoting and supporting activities of the MGA on $4^{\text {th }}$ September 2011. This campaign aims the users enabling to use satellites from different constellations simultaneously at the same time [1]. This is one example how a new international organization is evolved.

Scope of works of most of these organizations is wide enough; therefore several commissions within the organizations are established to work on the limited field of work. For example, in ISPRS, there are eight technical commissions and in each commission there are several working groups. Similarly in FIG there are ten technical commissions and in the same way there are several working groups in each commission. Each working group conducts activities defined by the organization and reports the achievements in their corresponding Technical Commission. Then each Technical commission also implements activities based on their corresponding scope of works and then report their own achievements along with the achievements of their corresponding Working Groups in the plenary session of the mother organization.

Some of the organizations have limited scope of works and so they handle the activities of the organization itself and conduct their regular activities based on their plan of action. For example, ISCGM has a very limited scope of work so the Committee has no commissions or working groups. The initiative of ISCGM is to prepare the spatial resolution of the global map database of $1 \mathrm{~km} \mathrm{x} 1 \mathrm{~km}$ that corresponds to a scale of 1:1 $\mathrm{M}$ for the printed maps [6].

The activities of most of the international professional organizations can also be generalized as follows:

- Conduct conference regularly in definite period of time interval

- Conduct General Assembly for discussing different issues related with its scope of works

- Share information on research areas and publicize the status and findings of the research work 
- Disseminate information through corresponding web portal

- Publish relevant information and data related to their corresponding domain

- Publish journal with high quality peer reviewed technical papers

- Publish code of conduct and professional ethics of the corresponding domain

- Inform its members and concerned communities about the achievements, coming activities, and other related information through hardcopy newsletter or e-newsletter

- Organize exhibition to demonstrate new technology and/or new products of the corresponding manufacturers

\section{Relationship between professional organizations}

As mentioned above, there exist so many national, regional and international professional organizations from the domain of Geo-informatics in the world. Resources in the Earth are limited so if the professionals have no communication, there could be duplication of work for the similar types of works which lead to the wastage of resources and also loss of time. So optimization in the use of resources is inevitable, that could be achievable only when there is communication and relationship between the organizations. In order to establish such relationship between the organizations, most of the organizations have made some provisions. Accordingly, governmental and national professional organizations can become member of regional and/or international organization. Similarly, regional organization can be a member of another regional organization and/or member of international organization. Some of the examples are as follows [2]:

- $\quad$ Survey Department is the member of Asia and Pacific Regional Space Agency Forum (APRSAF), Asian Association on Remote Sensing (AARS), Permanent Committee on GIS Infrastructure for Asia and the Pacific (PCGIAP), SAARC Networking on Cartography Arrangement (SNAC), International Steering Committee for Global Mapping (ISCGM), International Federation of Surveyors (FIG), Group on Earth Observations (GEO), Sentinal Asia Joint Project Team (SA JPT), et cetera

- Land Management Training Centre is the Member of International Federation of Surveyors (FIG) and Sentinal Asia Joint Project Team (SA JPT)

- Nepal Remote Sensing and Photogrammetric Society (NRSPS) is the member of Asia and Pacific Regional Space Agency Forum (APRSAF) and International Society for Photogrammetry and Remote Sensing (ISPRS)

- Nepal Institution of Chartered Surveyors (NICS) is the member of International Federation of Surveyors (FIG)

- $\quad$ Sentinal Asia Joint Project Team (SA JPT) is the sister organization of Asia and Pacific Regional Space Agency Forum (APRSAF)

- Asian Association on Remote Sensing (AARS) is the member of International Society for Photogrammetry and Remote Sensing (ISPRS) et cetera

The reasons to become the member of other professional organizations are as follows:

- $\quad$ The member organization will be invited to participate in the events organized by the organization

- The member organizations are eligible to participate in the General Assembly of the organization where the delegate can share the ideas

- The member organization will receive all the information and decisions of the organization

- The member organization receives opportunity to acquire knowledge on the status of research activities of the world. 
- Member organization sometimes receive opportunity to organize event of the professional organization

\section{Importance of Professional Organizations}

As a Geo-informatics professional, it is necessary to update professional knowledge, display talent, disseminate knowledge, and so on. The most appropriate platform for performing these activities is the events of professional organization where one could be part of the activity to contribute knowledge for development of profession. In other words, professional organization provides opportunity to participate in their events and these organizations are always trying to disseminate information and results of the research activities going around the globe through different means and media such as web portal, conference, newsletter, journal, et cetera. Based on these information and documents, institutions/organizations could modify existing system, develop suitable system, and conduct program to create awareness to the professionals and decision makers in the working field.

Any organization would like to establish a sustainable system to achieve its goal. This can be possible only when the professionals involved in the process possess professionalism. It is believed that the professionalism of the professionals may not be developed within the organization at work only but they should have some sort of affiliation with the professional organization(s) because, the professionals have better opportunities not only to broaden their horizon but also to enhance the knowledge, if they participate the activities of the professional organizations. This will, in turn, motivate them to display their professionalism [4]. Therefore, there is a high importance of professional organization for the sustainable development of profession.

\section{Beneficiaries}

The outcomes and achievements from the activities of the professional organizations are always beneficial to several sectors such as individual professionals, national institutions and even the country itself in different ways.

For instance, individual professional will be benefitted as follows:
- Acquire knowledge on several aspects of the profession

- Develop skill to prepare a research paper and to discuss with the counterparts

- Create opportunity to give own exposure with the foreign professionals

- Gain experiences for conducting an event in the organization

- Create opportunity to display professionalism in the profession

- Get opportunity to understand the culture of the country and to observe exciting and important sites of the organizing country

National institutions will be benefitted from the following aspects:

- Participated staff will motivate to feel ownership and responsibilities for the organization and dedicate to work harder than before

- Increase efficiency of the individuals at their workplace

- Create environment to apply newly develop technologies for increasing its efficiency

- Support in the capacity development within the institution/organization

- Get exposure of the institution in the international forum

- Receive opportunity to understand the status of similar institutions of the participating countries

Similarly, if the event is organized in the country, it will also be benefitted, in the following way:

- Enable to participate a large group of professionals of the country at one time

- Enable to develop sustainable technological system

- Support in the promotion of tourist industry and create environment to earn foreign currency in the country which are spend by the foreign participants

- Create environment to exchange culture with the foreigners 
- Increase employment opportunity in different business sectors

- Recognize the country and related organizations by the world community

\section{Conclusion}

Professionals should have affiliation with the professional organizations to develop their professionalism. It is clear that the Geo-informatics professional organization could be national, regional or international. Each of these organizations has their own objectives and means to disseminate information to the professionals. There are provisions to establish relationship between different categories of the organizations. The easiest mean is to become the member of the other professional organization(s). The professionals, national institutions and even the country itself can receive several benefits from the activities, outcomes and documents of the corresponding professional organization. This will create environment to develop sustainable system in the institution. Thus, the professionals recognized the Geo-informatics professional organizations around the world are important organizations, specifically, for development of the career as well as for development of sustainable technological system.

\section{References}

Rabin K. Sharma; GNSS in the path of Using MultiGNSS, published in the Earth Observation: an annual Newsletter, Volume V/April, 2013

Rabin K. Sharma; Involvement of Survey Professional Organizations of Nepal in International Activities; published in Nepalese Journal on Geoinformatics, Number 9, 2010.

Rabin K. Sharma; Profession and Professional Organizations in Nepalese Context; presented in $X{ }^{\text {th }}$ ISPRS Congress 2008, Beijing China; July 3-11, 2008

Umesh Kumar and Rabin K. Sharma; Need of Professionalism in Geomatics Profession for the Development of Sustainable System, published in the Nepalese Journal on Geoinformatics, Number 8, 2009.

www.aprsaf.org

www.iscgm.org

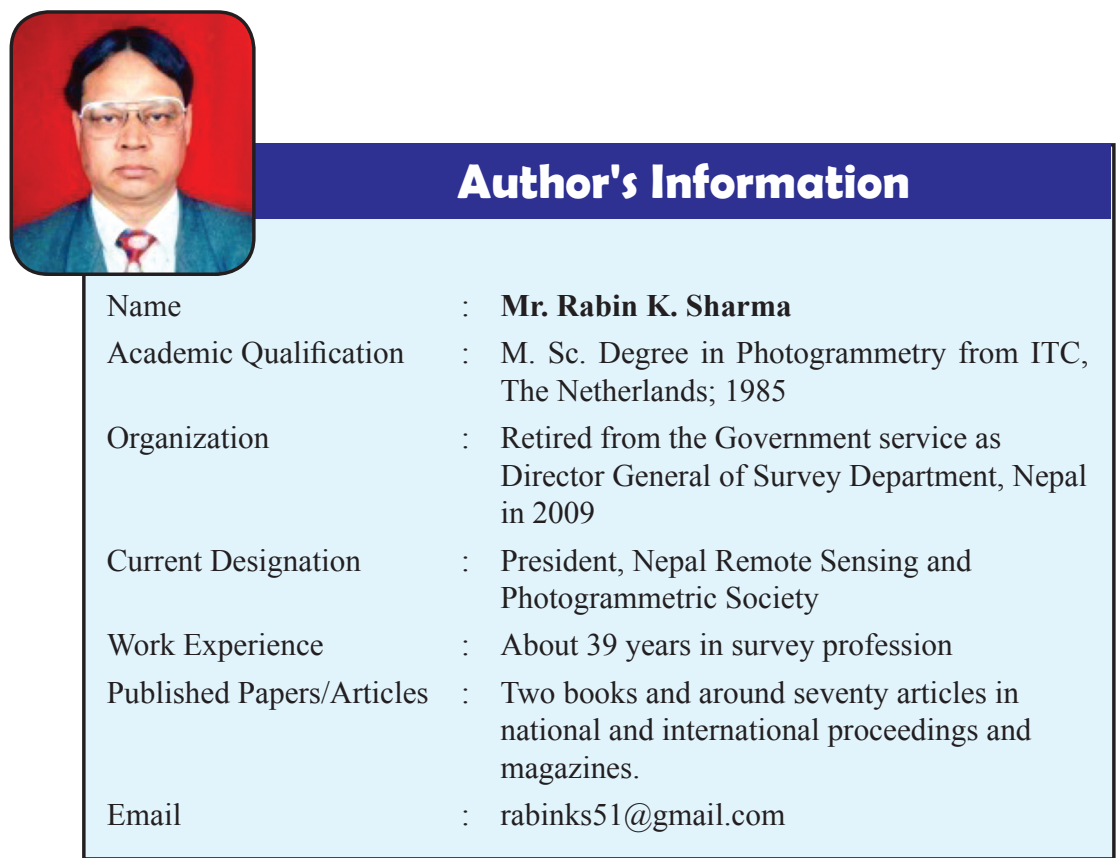

